\title{
Immuno-toxicological Evaluation of the Adjuvant Formulations for Experimental Anti-meningococcal Vaccines without Aluminium Hydroxide
}

\author{
BEATRIZ TAMARGO SANTOS ${ }^{1}$, SIMONA BUNGAU ${ }^{2}$, CATHERINE FLEITAS PEREZ ${ }^{3}$, YANET MARQUEZ NAPOLES ${ }^{4}$, \\ JUAN F. INFANTE BOURZAC ${ }^{5}$, REINALDO OLIVA HERNANDEZ ${ }^{5}$, WENDY RAMIREZ GONZALEZ ${ }^{6}$, GABRIELA CIOCA*, \\ LOTFI ALEYA ${ }^{8}$, V. GUSTAVO SIERRA GONZALEZ ${ }^{9 *}$ \\ 'Department of Immunology, Latino American School of Medical Sciences of Havana (ELACM), Havana, Cuba, \\ 2University of Oradea, Department of Pharmacy, 10, 1 Decembrie Sq., 410073, Oradea, Romania \\ 'Department of Pharmacology and Toxicology, Pharmacy and Foods Institute (IFAL), University of Havana, Cuba \\ ${ }^{4}$ Department of Molecular Biomedical Sciences, North Carolina State University, Raleigh, United States of America \\ ${ }^{5}$ Finlay Institute for Vaccines, Havana, Cuba \\ ${ }^{6}$ Department of Allergens, National Centre of Bioproduts (BIOCEN), Havana, Cuba \\ ${ }^{7}$ Lucian Blaga University of Sibiu, Faculty of Medicine, 10 Victoriei Blvd., 550024, Sibiu, Romania \\ ${ }^{8}$ Bourgogne Franche-Comte University, Besancon, France \\ ${ }^{9}$ BioCubaFarma, Havana, Cuba
}

\begin{abstract}
The proteoliposomes and cochleates are used as adjuvants for vaccines since they are potent immune stimulators. However, the hyper stimulation of the immune system provoked by adjuvants can cause immunetoxicological side effects. The present study was carried out to evaluate the toxic and immuno-toxicological effects of new adjuvants for anti-meningococci vaccines based on neo-proteoliposomes (nPL) and neocochleates ( $\mathrm{nCh}$ ), in Balb/c mice that were administered doses of $15 \mu \mathrm{g}$ each, over periods of 14 days through intramuscular route and three inoculations with the same doses through intranasal route, every 7 days. The Scanning and Transmission Electron Microscopy showed that the nPL and nCh had nanometric dimensions and their normal peculiar forms. The experimental formulations did not provoke general toxic effects in the tested animals, which tended to the progressive normal growing of this species, that did not statistically differ from the control ones. The studies of pathologic anatomy in inoculation organs and sites did not reveal modifications that can indicate toxicity and there was no sign of hepatic damage. The structural observations found in the spleen and lymphatic nodes showed the physiological development of the immune response, which was normal in all cases showing the restitution of the stimulation signs. The relative weight values of the spleen were within the standard range. These results showed that the $N P L$ and $n C h$ elaborated as adjuvants for vaccines did not show any evident induction of general toxic or particular immune-toxicologicl effects.
\end{abstract}

Keywords: immunotoxicology, adjuvants, nanoparticles, cochleates, proteoliposomes.

Vaccines are one of the most successful medical invention of the last century. Their importance has evolved and today they are classified from a wider perspective that comprises the prophylactic and therapeutic vaccines [1]. Nevertheless, it is obvious that future vaccines will require new adjuvants with predictable activity [1,2]. The adjuvants allow, among other functions, to manipulate and control the interaction between antigens and the immune system of the body. Aluminium salts or hydroxide are between the mostknown and used adjuvants in human beings; however, they have some toxicological and immunological disadvantages [3,4]. Actually, the small availability of safe and efficient adjuvants has enormously limited the development of effective vaccines.

The vaccines with accurate molecular structures of the new generation are presented as proteoliposomes $(\mathrm{PL})$ and cochleates (Ch), whose particle structures allow them to function as drug delivery carriers and adjuvants, enhancing or modulating immune responses to antigens, with a high level of purity.

Obtaining PL or vesicles, derived from the outer membrane of the $\mathrm{N}$. meningitidis (NMB) serogroup, as antigenic component of the VA-MENGOC-BC ${ }^{\circledR}$ antimeningococcal vaccine, was one of the most successful approaches to the protection against disease caused by this microorganism $[5,6]$. PL are nanovesicles that contain lipopolysaccharides (LPS) and phospholipids, proteins of the bacterial outer membrane [5-9]. The immunological properties of these PL have been widely studied to demonstrate their capacity to induce Th1 immune responses $[6,10,11]$. The PL transformation into $C h$ applied to VA-MENGOC-BC ${ }^{\circledR}$ vaccine allows to increase the stability of its components preserving the pathogen associated molecular patterns (PAMPs) derived from the bacterial surface of the meningococcal $B$, increase the resistance to an aggressive environment as well as the interaction with the cells of the immune system [12]. Ch are formed as a result of the interaction of vesicles from anionic lipids with bivalent ions such as the $\mathrm{Ca}^{2+}[13,14]$. Thus, these structures become efficient candidates for mucosal vaccines which constitute a less invasive way of immunization.

$\mathrm{PL}$ and $\mathrm{Ch}$ can be nanoparticles (NP), depending on their dimensions, which can potentiate both the humoral and the cell-mediated immunities to antigens of all kinds and they can guarantee a stronger presence in the cells with antigens [15]. Studies of vaccine formulations based on NP have demonstrated their potential efficacy due to 
their own adjuvant properties. The interaction between the NP and the human immune system can lead to an immunomodulation that can be beneficial or not, according to its therapeutic objective [16].

The hyper-stimulation potential of vaccines can unleash adverse immuno-toxicological effects [17]. The risk of a systemic inflammatory response has increased with the emergence of new experimental adjuvants [18]. The stimulation of the immune response has to be carefully measured, since a hyper-activation can produce cytotoxic and autoimmune responses, among others, which could be more destructive than expected. Today, the search for new, more potent and safer adjuvants represents a scientific challenge. Consequently, the efforts for global harmonization towards improved and consistent standards of nonclinical and clinical evaluation are required to better assess the safety of preventive vaccines and predict their toxicity [19]. The toxicology studies of the vaccine formulations based on NP are few, and so far, there aren't official regulatory guides with these purposes. Nevertheless, every day is more acute the need to incorporate the immune-toxicity trials into the medicine preclinical studies that have the immune system as their main goal, such as the future vaccine candidates, since they reveal important information about their efficacy and safety.

Therefore, considering all the previous statements and the fact that we wanted to explore the anti-meningococcal vaccines from another point of view (immunotoxicological) than the issues already approached in our previous paper [6], in the presentstudy have been evaluated immuno-toxicological parameters of the new adjuvant formulations with PL and Ch nanoparticles (that have been designed with immune-modulator properties). The experiments were made using the Balb/c mouse model.

\section{Experimental part}

Materials and methods

Adjuvant vaccine formulations

The adjuvant vaccine formulations were designed using as antigen NMB proteins complex extracted and purified, which have been classified as differentiated proteins (PD). They were mixed with immunomodulator components that had a defined molecular structure, in order to produce two formulations groups ( 1 and 2), presenting the structures of neo-proteoliposomes (nPL) and neocochleates ( $\mathrm{nCh}$ ). The obtained formulations were named AlF1-nPL, AlF1-nCh, AIF2-nPL and AIF2-nCh. The liposomes were elaborated from a mixture of dioleoyl phosphatidyl serine (DOPS) and cholesterol (Sigma Aldrich Co.), through the dehydration/rehydration procedure (using a modification of the procedure of dehydration/rehydration described in literature [20]). The cochleates resulted in the process of calcium chloride $(0.1 \mathrm{M})$ addition to the suspended preformed liposomes [14]. As controls were applied a suspension of buffer PD proteins complex (TrisHCL $5 \mathrm{mM}$, detergent $0.1 \%, p H$ 7.4) named PD-Tp, a preparation of VME from NMB, in a similar buffer solution that takes as detergent $0.1 \%$ of sodium deoxycholate as the Cuban anti-meningococcal VA-MENGOC-BC $\otimes$ vaccine from the Finlay Institute.

\section{Characterization of $n P L$ and $n C h$ through Transmission and} Scanning Electron Microscopy (TEM and SEM)

The electron-microscopic images were obtained through TEM, with a CM12 Phillips microscope. The samples were treated by negative staining, using the classic drop method. After placing $5 \mu \mathrm{L}$ of $\mathrm{nPL}$ and $\mathrm{nCh}$ formulations all together on a coated coal microscope slide (little grates of copper coated with coal), the samples were stained with phosphor-tungstic acid at $2 \%$ and observed at 31x to 730 000x magnification. For the SEM, one drop was applied to the different formulations on a glass microscope slide and they were dried at a room temperature for $12 \mathrm{~h}$. Afterwards, they were coated with a thin gold-palladium layer and were put in a LEICA 440 scanning electron microscope. The images were observed at $15 \times$ to $290.000 \times$ magnification.

\section{Experimental animals and their maintenance}

Specific pathogen-free male Balb/c mice (6-8 weeks old, approx.18 g weight) were obtained from the Centre of Laboratory Animal Production (CENPALAB, La Havana, Cuba). The mice were cared according to the guidelines established by the Guide for the Care and Use of Laboratory Animal, 2010, and the institutional regulations of the National Centre of Bioproducts (BIOCEN), with the permission and complete Experimental Protocol approval of the Ethics Committee of this centre. Mice were housed in a polycarbonate cage, in a room with controlled temperature and humidity, and given food and water $a d$ libitum [6].

\section{Study design}

For the experiments, 130 animals were randomly distributed in 13 groups ( 10 animals / group). The formulations were intra-muscularly (IM) and intra-nasally (IN) administered. The immunization schedule comprised two inoculations, as follows: first, at the beginning of the study; second, after 14 days. It was administered a dose of $15 \mu \mathrm{g}$, referring to the protein concentration, in $250 \mu \mathrm{L}$ of phosphate buffer saline (PBS). The mice were injected in the left quadriceps of the back extremities through intramuscular deep puncture. The IN immunization consisted of three inoculations, every 7 days, with a dose of $15 \mu \mathrm{g}$, referring to the protein concentration, in $25 \mu \mathrm{L}$ of PBS ( 12.5 $\mu \mathrm{L}$ per each nostril). The VA-MENGOC-BC ${ }^{\circledR}$ vaccine was IM administered, while the VME of NMB was IN given. It was also included a negative control group (NC), to which a PBS was administered. The same schemes of immunization was used in one of our previous study [6].

\section{Clinical observations}

Every day there were observed and checked behaviour variations, general physical conditions, skin and mucosa changes, emergence of secretion, colour or loss of hair, skin reactions, piloerection, exhaustion, involuntary movements, ataxia, excitation, as well as water and food consumption. Special emphasis was considered on the IN inoculated animals with respect to the emergence of manifestations, such as: nostril irritation, sneezing, dyspnoea, head shaking, and salivation, watering and nasal secretions. Besides, the inoculated sites were examined to seek erythema, sloughs and oedemas signs. Their abdomens and thoraxes were palpated. The feces were checked regularly to detectany alteration. Special attention was paid to the regression of any local symptom, if there were any, every 7 days after each inoculation.

\section{Body weight performance and spleen relative weight}

Animals were weighed at the beginning and end of the study with Sartorius technical scale. At the end of the study the spleen weight was obtained with an A200S (0.0001 g) Sartorius analytic scale, using the spleen weight ( $g$ )/animal weight $(\mathrm{g})$ ratio. Animals were weighed at the beginning and end of the study with an A200S (0.0001g) Sartorius 
analytic scale. At the end of the study the spleen's relative weight (SRW) was obtained, using the spleen weight (g)/ body weight (g) ratio.

\section{Necropsy and organ tests}

The mice were sacrificed through cervical dislocation, 21 and 60 days after the administration of the last doses. After 21 days, the necropsy of three animals of each group was carried out, and at the end of the study, after 60 days, the rest of the mice were also necropsied. Anatomic macroscopic and microscopic alterations were registered in the following organs: liver, pancreas, large intestine, nose, muscles of the back-left extremity, salivary glands (parotid and sub-maxillary), bone marrow, thymus, spleen and regional lymphatic nodes (mesenteric, deep inguinal groin, popliteal, cranial deep cervical, parotid and mandibular).

\section{Histological analysis}

After the anatomic test of the organs the histological test was carried out. The tissues were put in 10\% neutral formalin and embedded in paraffin wax. Sections were stained with Haematoxylin and Eosin for the determination of cellular infiltrates. Five samples of every organ or tissue belonging to each autopsied animal were observed.

\section{Statistical analysis}

The mean \pm standard deviation was determined for each group of a given experiment. The data were analysed with the Statgraphics statistical package using one-way analysis of variance (ANOVA) followed by Duncan and Dunnett's method. Mean comparisons were performed by using the Mann-Whitney test. Statistical analysis was performed using Statistical program, Windows 6.0. The criterion for significance was set at $p \leq 0.05$.

\section{Results and discussions}

\section{Characterization through Eeectron microscopy}

In figure 1 are shown $\mathrm{nPL}$ and $\mathrm{nCh}$ images obtained by TEM and SEM from the adjuvantformulations. In the microphotography $1 \mathrm{~A}$ is observed the spherical shape of the $\mathrm{PL}$, which is a characteristic of this structure and some values of the particles' sizes, smaller than $100 \mathrm{~nm}$; the surface of these structures is shown in 1B; in both images, the shape and size homogeneity can also be observed. In figure $1 \mathrm{C}$ is show $n$ a cylindrical, very thin, long particle, diameter $<10$ $\mathrm{nm}$, similar to a hand-rolled cigarette. In figure $1 \mathrm{D}$, the surfaces of many long and cylindrical particles are identified with arrows. These supra-molecular structures confirm the cochleates aggregate formations, which result from the
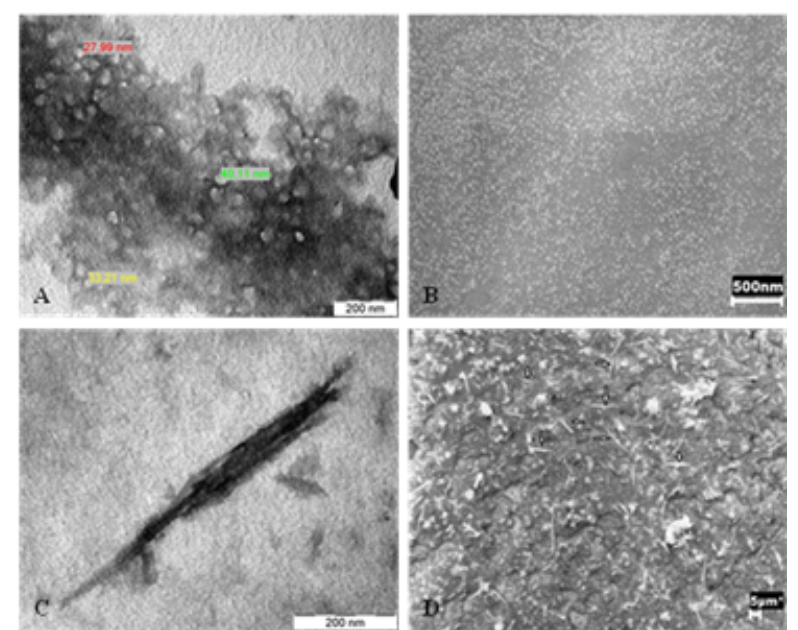

Fig. 1. A and C: TEM with a PHILIPS CM-12 microscope, 500.000x magnification, $60 \mathrm{kV}$ voltage. B and D: Microphotographs obtained by means of SEM, with LEO-440 VP, 100.000x magnification. Nanometric structures: LP ( $A$ and $B$ ) and Ch ( $C$ and D) were observed. In D, Ch are pointed with arrows; the image in the bottom was caused by an excess of proteins in the sample [6]

superposition of lipid bi-layers that interlace to form multilayer aggregates $[6,21]$.

General toxicity and effects of AIF1-nPL, AIF1-nCh, AIF2nPL and AIF2-nCh vaccine adjuvants on body weights

None of the administered formulations affected the animals' vitality or their lives during the experiment. There were not clinical signs of general toxicity or alterations in the behavior that could have been provoked by the administered experimental vaccines. There were not considerable differences regarding water and food consumption. Animals grew up progressively and normally.

In table 1 are presented the results of the statistical bodyweight comparison at the start and end of the study. All mice became significantly heavier, with respect to the starting weight $(p \leq 0.05)$. The animals' final weights from each group were compared through IM route in relation to the $\mathrm{CN}$ and $\mathrm{VBC}^{\circledR}$ groups and through IN route with regard to the $\mathrm{CN}$ and VME groups. The results did not show statistical differences among them $(p \geq 0.05)$.

Effects of AlF1-nPL, AlF1-nCh, AlF2-nPL and AIF2-nCh vaccine adjuvant in organs and tissues through histopathologic techniques

In the studied groups, no structural changes or topographyalterations have been found (thatmightindicate

Table 1

EFFECTS OF AIF1-nPL, AIF1-nCh, AIF2-nPL, AND AIF2-nCh VACCINE ADJUVANTS ON Balb/c MICEa BODY WEIGHTS

\begin{tabular}{|c|c|c|c|c|c|c|c|c|}
\hline \multirow{2}{*}{ Group } & \multicolumn{2}{|c|}{ AIF1-nPL } & \multicolumn{2}{|c|}{ AIF1-nCh } & \multicolumn{2}{|c|}{ AIF2-nPL } & \multicolumn{2}{|c|}{ AIF2-nCh } \\
\hline & $\mathrm{IM}$ & IN & $\mathrm{IM}$ & IN & $\mathrm{IM}$ & IN & IM & $\mathbb{I N}$ \\
\hline Initial & 16.280 & 19.503 & 15.457 & 19.150 & 16.898 & 18.270 & 16.565 & 19.893 \\
\hline Weight & \pm 1.256 & \pm 0.774 & \pm 0.437 & \pm 1.619 & \pm 1.037 & \pm 1.170 & \pm 0.727 & \pm 0.289 \\
\hline Final & 25.35 & 25.60 & 23.830 & 25.457 & 25.350 & 24.650 & 25.883 & 27.190 \\
\hline Weight & $\pm 1.958^{\circ}$ & $\pm 0.293^{*}$ & $\pm 0.457^{8}$ & $\pm 1.088^{*}$ & $\pm 1.826^{\circ}$ & $\pm 0.368^{*}$ & $\pm 1.809^{*}$ & $\pm 1.830^{8}$ \\
\hline \multirow{2}{*}{ Group } & \multicolumn{2}{|c|}{ PD-Tp } & \multicolumn{2}{|c|}{ VBCE } & \multicolumn{2}{|c|}{ VME } & \multirow{2}{*}{\multicolumn{2}{|c|}{$\mathrm{CN}$}} \\
\hline & $\mathrm{IM}$ & IN & & & & & & \\
\hline $\begin{array}{l}\text { Initial } \\
\text { Weight }\end{array}$ & $\begin{array}{l}17.473 \\
\pm 0.742\end{array}$ & $\begin{array}{l}19.523 \\
\pm 1.737\end{array}$ & \multicolumn{2}{|c|}{$21.470=0.836$} & \multicolumn{2}{|c|}{$17.378 \pm 1.522$} & \multicolumn{2}{|c|}{$16.974 \pm 1.453$} \\
\hline $\begin{array}{l}\text { Final } \\
\text { Weight }\end{array}$ & $\begin{array}{c}25.910 \\
\pm 1.955^{\circ}\end{array}$ & $\begin{array}{c}24.828 \\
\pm 1.662^{*}\end{array}$ & \multicolumn{2}{|c|}{$28.877=1.622^{*}$} & \multicolumn{2}{|c|}{$25.280 \pm 1.122^{*}$} & \multicolumn{2}{|c|}{$25.386 \pm 1.078^{*}$} \\
\hline
\end{tabular}

${ }^{2}$ Number of Balb/c mice tested: 10/group. IM: immunized mice groups with two doses of $15 \mu \mathrm{g} / 250 \mu \mathrm{L}$ from each of the adjuvant formulations through intramuscular route. IN: immunized mice groups with three doses of $15 \mu \mathrm{g} / 25 \mu \mathrm{L}$ from each of the adjuvant formulations through intranasal route. Negative Control (NC) mice were immunized with PBS only. Data are presented as mean $\pm \mathrm{SD}$. Non parametric test of Mann-Whitney.

${ }^{*}$ The $p$ value to compare was $\leq 0.05$. 
functional changes in the analysed organs). The histological studies did not show diagnostic changes that could have been caused by any toxicity process. It is important to point out that there was no sign of hepatotoxicity in any of the mice. In the anatomic test of the inoculation site, the administration zones were explored through the IM and IN routes. We detected macroscopically limited small whiteyellow zones in the animals' back left limb of the VBC ${ }^{\circledR}$ group thathad aluminium hydroxide as one of the adjuvants. In the IM immunized animals, the histological analysis of the back-left limb's muscular tissues did not show damages in any of the groups, except for the VBC ${ }^{\circledR}$ group.

In these animals, it was detected a local inflammatory tissue reaction known as granuloma with a cellular polymorphic infiltrate with many lymphocytes and macrophages (fig. 2a). In figure $2 b$ was observed, in the cytoplasm of the macrophages, the accumulation of a homogenous basophile substance, presumed to be aluminium hydroxide. These accumulations were found in animals which were sacrificed at the end of the study. The histopathologic analysis of the IN immunized animals
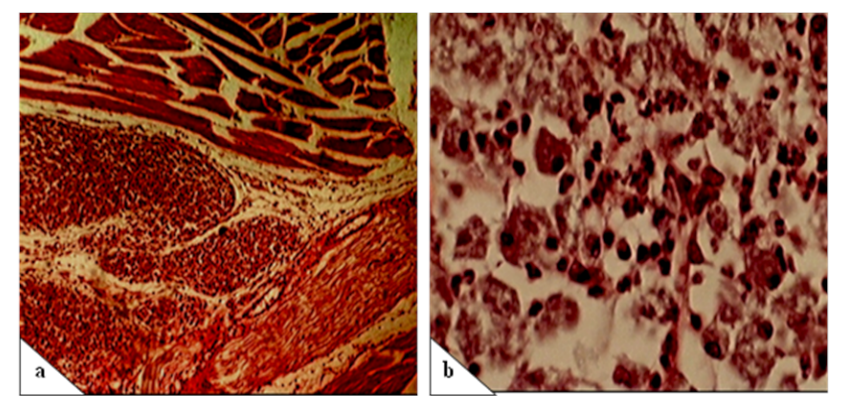

Fig. 2. Microphotographs of histological muscle cuts of the backleft extremity from $\mathrm{VBC}^{\circledR}$ animal group $(n=3)$ after 21 days. a:

Granuloma with cellular infiltrate where lymphocytes,

polymorphonuclear leukocytes and abundant macrophages are observed (HE 100x). b: Abundant macrophages of $\mathrm{Al}(\mathrm{OH})_{3}$ (HE 450x)

included the nostrils and did not reveal lesions that might indicate irritation, inflammation or local toxicity symptom.

Effects of AIF1-nPL, AIF1-nCh, AIF2-nPL and AIF2-nCh vaccine adjuvants on the relative spleen weight and organs of the immune system

In figure 3, are shown the comparison results of the relative spleen weight (RSW) in the experimental groups in relation with the CN group as well as the $\mathrm{VBC}^{\circledR}$ and VME control groups in the IM and IN routes respectively. As it is observed in figure 3A, the administered AIF1-nPL, AlF2nPL and PD-Tp groups through IM route and AIF1-nPL group through IN route (fig. 3B) $(p \leq 0.05)$. The broken lines represent the normal values (approximately 0.004) (Kim et al., 2007) and the value range for RSW immunized animals applied to mice Balb/c $(0.005-0.0085)$ [21].

Figures $4 a$ and $b$ representa histological cut of the bone marrow and the thymus, which was normal in all groups.

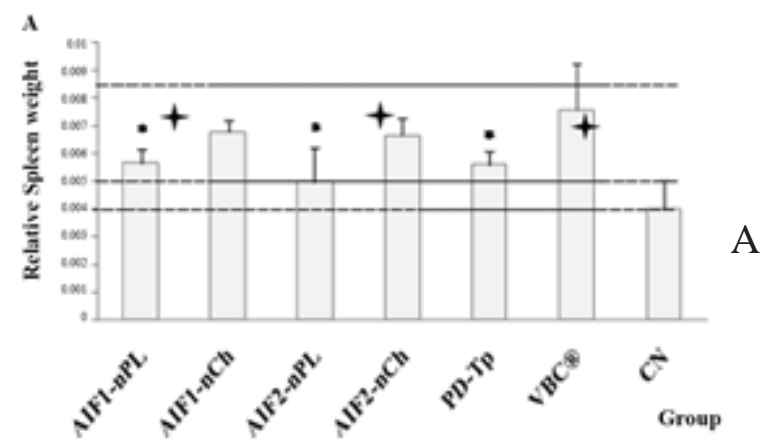

Fig. $3 \mathrm{~A}$

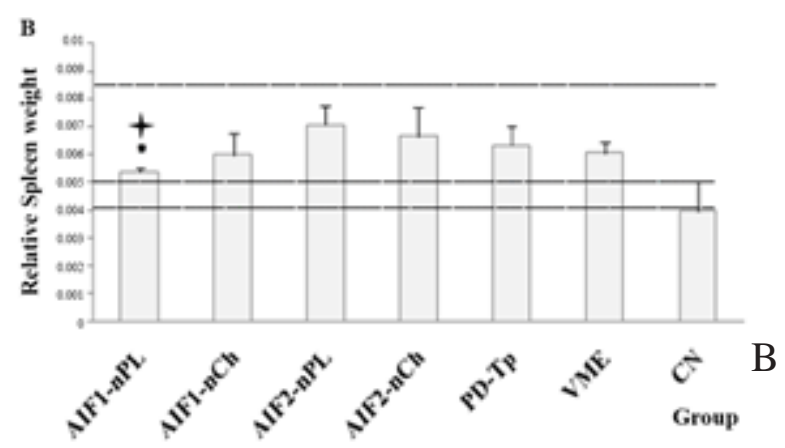

Fig. 3. Relative spleen weight. Each value represents \pm standard deviation of immunized animals through IM (A) and IN (B). *p $\leq 0.05$ significant differences with respect to a $\mathrm{CN} .+p \leq 0.05$ significant differences with respect to $\mathrm{VBC}^{\circledR}$ group for the IM route and with respect to VME group for the IN route. Non parametric test of Mann-Whitney
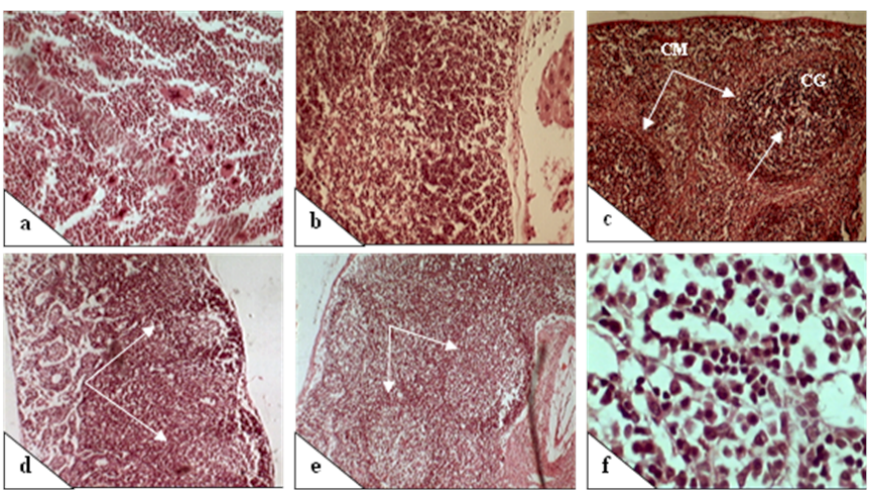

Fig. 4. Representative microphotographs related to mice $(n=3)$ of the AIF1-nPL, AIF1-nCh, AIF2-nPL, AIF2-nCh, PD-Tp, VBC ${ }^{\circledR}$ and VME

groups. (a) bone marrow with abundant megakaryocytes; (b)

thymus cut presenting a histological normal pattern; (c)

histological cut of the spleen with hyperplasia; CM corpuscle of

Malpighi and CG: germinal centres. (d) lymphatic node with subcapsular secondary; (e) paracortical follicles are pointed with arrows; (f) (HE 100x), abundant lymphocytes and plasmatic cells in the helium (250x)

In AIF2-nPL and PD-Tp adjuvant immunized group, the microscopic spleen analysis revealed splenomegaly in one of the three animals, according to the histological study. Slight hyperplasia of spleen was observed after 21 days (fig. 4c) in AlF2-nPL, PD-Tp and VBC ${ }^{\circledR}$ groups, immunized with pro-inflammatory formulations through IM route, as well as AIF1-nPL, AIF1-nCh and AIF2-nCh group through IN route. However, this hyperplasia was transitory since it disappeared 60 days later.

In lymphatic nodes, structural or topographicmacroscopic alterations were not observed, except in two or three animals of the AIF2-nCh group, in which a congestion and slight size increase were perceived. The histological studies of IM and IN administered mice groups show ed secondary sub-capsular follicles in popliteal node and in mandibular lymphatic node, respectively (fig. 4d). This phenomenon was also found in AIF1-nPL group, in which were also observed paracortical follicles and many plasmatic cells in the hilum (fig. 4e and f). In all cases the histological observations were transitory and disappeared at the end of the study.

Nowadays, assessment of immuno-toxicological effects relies on different animal models. Nevertheless, in vitro assays, as well as in vivo models, are also needed to detect immune-stimulation and autoimmunity [22]. It is accepted that, with regard to adjuvants, potency and toxicity must be balanced in order to provide maximum 
immune stimulation with minimal side effects [23]. Nevertheless, this balance can be also controversial in a way, because the same mechanisms that are responsible for the positive immune stimulation effects can provoke side effects. Over the last twenty years research has provided an important insight of the immuno-toxicity mechanisms against local and systemic adverse reactions through immune stimulation drugs and adjuvants. Very few adjuvants have been licensed to be used in prophylactic vaccines because of the toxic properties detected during pre-clinical or clinical studies of all the new candidates being evaluated. Unfortunately, there are several challenges in the design of adequate safety studies [18].

The elaborated formulations used as adjuvants (AIF1 and AIF2), the $\mathrm{nPL}$ as well as the nCh are nanoparticles considering their dimensions. Nanoparticles usually have immune stimulatory properties such as antigenicity, adjutancy, and inflammatory responses [24]. It is known that they are able to stimulate innate and adaptive responses and the secretion of inflammatory cytokine. They have been applied as vaccine adjuvants $[25,26]$, although there are evidences about their suppressing effects [27], they can cause strong hyper-sensibility reactions and anaphylaxis. The manipulation of the physical-chemical characteristics of nanoparticles has been very important to reduce their toxic effects which are caused by the interaction among them and the immune system, which can lead to an immunomodulation, beneficial or not, depending on its therapeutic objective [15]. All these aspects stress the importance of checking at least in the pre-clinical studies the possible general toxic effects particularly on the immune system, of the new adjuvant formulations evaluated in this work.

A unique dose for this study was chosen through IM and IN routes, considering that it is similar to the ones that were used in other vaccines. The results of the heavier weights and the animal clinical studies are elementary and sensible indicators for the toxicity and/or safety of a biological product [28]. In fact, these parameters are part of the general and specific toxicology trials demanded by the regulatory organisms to predict the toxic potential of any substance [29]. In this study all animals showed a tendency to a progressive growth until the end of the experiment, which is related to what has already been stated about this species [30]. The animals that were immunized with the experimental formulations did not weigh differently from the average weight of control groups.

The studies of pathologic anatomy carried out for the tested organs did not reveal modifications that might indicate toxicity. We have to point out that there were not hepatic alterations, what is extremely important since this organ is very sensible to toxicity. The structural observations found in the secondary lymphoid organs showed the physiological development of the immune response. None of them was different from what was expected.

The damage emergence in the inoculation sites usually has an important toxicological value in relation to vaccines. The local tolerance trials for vaccine products constitute essential regulatory requirements of the preclinical toxicological studies. In the adjuvant-formulation immunized groups there were no local inflammatory symptoms that showed adverse reactions in the inoculation sites. How ever, in animals from VBC ${ }^{\circledR}$ group, were observed granulomas with abundant macrophages in the muscle of the left back limb caused by the aluminium hydroxide. This lesion remained until the end of the study, a proper characteristic and that is provoked by the depositadjuvants that are associated to the high antibodies titles and tend to evolve towards a restoration process where the infiltrating cell population is reduced, and the formation of scar tissue is induced becoming a local fibrosis [31-33]. This effect has been described in toxicological studies of other vaccines that contain this substance [34-37]. Infiltrations of aluminium containing macrophages gathered around the muscular fibres in the myofascii were observed in occasional deltoid muscular biopsies from vaccinated patients [38]. This local reaction, described in adults and children [39,40], was characterized by the presence of $\mathrm{Al}(\mathrm{OH})_{3}$ - loaded macrophages. This phenomenon was named MMF (macrophagic myofasciitis) and was attributed to the persistence of aluminium hydroxide for years at the site of a previous intramuscular injection [41]. Some studies have related the presence of such aluminiumcontaining macrophage manifestations to various clinical conditions, such as myalgia, muscle fatigue and, more controversially, to neurological disorders with no obvious etiological relation to the vaccination [42].

The selected route of administration may influence the emergence of side effects associated with adjuvants. With the intramuscular route (IM), swellings of similar sizes may be less easily palpable as they are located deeper within the tissue. In addition, the intramuscular routes that are as innervated with sensory neurons as the skin $[43,44]$, evaluated the local toxicity of several adjuvants after the intranasal vaccination of guinea pigs. Damage was found in the mucosal epithelium caused by the direct toxicity of a given inoculum. This can lead to the contact of lymphoid cells with the submucosal tissue or draining lymphatic vessels, causing immunological responses in which antigen uptake is carried out by M cells [44]. Another concern when using the nasal route for immunization is the potentially directpassage of the inoculum into the brain through the olfactory pathways [45]. The results of this work did not reveal anatomopathological alterations in the nasal zone, including the dorsal and ventral cornets. Similar results were described previously [46].

The usual methodology to determine the immunotoxicological effects of a xenobiotic is the design of upgrading studies comprising different levels and following an evidence strategy [47]. Variations in the weights of relevant organs of the immune systems such as thymus, spleen, lymphatic nodes, and bone marrow indicated a potential toxicity on these organs and the immune system 48-50]. Due to its importance, this value is included in the immunopathological trials of the most importantimmunotoxicological studies [51,52]. Therefore, the RSW was considered a toxicity indicator, because it is a response organ, involved in many functions of the immune system and it can be very vulnerable to any damage.

The RSW values in all experimental groups were found in normal value range for immunized animals and are related to the expected immunological stimulation. All experimental and control adjuvant formulations through both IM and IN routes lead to a RSW increase which can be compared and can be higher than the new formulations without Al $(\mathrm{OH})_{3}$ when compared to normal figures of the RSW parameters for the isogenic species. Some groups showed figures lower than the RSW from the statistical point of view, however in relation to control groups, from the physiological point of view, they showed better responses of the control vaccine rather than suppressing signs (these figures are not shown). Apart from that, stimulation provoked by these formulations through the chosen inoculation route should be more intensive in a local zone and in the lymphatic nodes rather than in the spleen, since these nodes are close to the inoculation sites which are preferential for the induction of immune 
responses. This could be the reason for a relatively slight reduction of the spleen cellularity favouring a possible cell migration from this organ to the lymphatic nodes, which are stimulated peripheral lymphatic organs provoking a slight transitory reduction of this organ's relative weight and reaching the maximum cellular migration towards induction sites, as it occurs in the plantar pads when stimulating with antigens, and where true cell groups can be perceived (figures are not shown). Short after, this relative transitory reduction is compensated from homeostatic point of view. The anatomic, macroscopic and histological analysis of the spleen carried out to each group did notshow any kind of atrophy or alteration of the morphological structure, damage signs, dead splenocytes, reduction, white pulp atrophy or tissue destruction [53], as observed in immune-toxicity studies of immunosupressing complexes that have presented pathological values below 0.0030 [54]. The relative weight reduction of the spleen in our study does not constitute an alteration from the physiological point of view that might be considered pathological or a suppressing consequence of immune-toxicological modulation.

The absence of anatomic and histological alterations in the bone marrow and the thymus in the autopsied animals meant the absence of the toxicity that might be caused by the new studied vaccine adjuvants in these organs. This is significant from the immuno-toxicity point of view since in these immune primary organs the cells that guarantee the immune system's correct functioning are generated and specialized. The spleen's slight hyperplasia in some cases was related to the immunologic stimulation response and it was also reversible. The Malpighi corpuscle hyperplasia can be stimulation evidence provoked by the adjuvant formulations in the spleen, which was fading away until the 60th day but contributed to a higher intensity of the immune response. These alterations are logical considering the administration of immunogenic formulations. The fact of not being detected at the end of the experiment indicates that they were balanced as a result of the normal kinetics of the immune system. In vaccines, the immune stimulation is an intentional pharmacological effect, that is why parameters as inflammation and lymphoid hyperplasia are expected [17]. In our case the lymph-node hyperplasia with abundant plasmatic cells in the medullar zone is an example of the immunological stimulatory activity and is a suitable efficacy indicator of the evaluated adjuvants for vaccines from the physiological view point.

\section{Conclusions}

To sum up, adjuvant formulations for AIF1 and AIF2 vaccines both in $n-P L$ and $n$-Ch forms did not cause local or systematic toxicity on any of the immune system organs, at least according to the last evaluations of this study. They showed efficacy and safety, which is an advantage with respect to adjuvant formulations that used aluminium hydroxide.

Acknowledgements: The authors specially thank to Prof. Dr.C. Antonio Mourino, University of Santiago de Compostela, Spain, who supported us with the electron-microscopy studies and to DrC. Alexis Labrada Rosado, Virgilio Bourg, Damaris Torralba, and Leonela Garcia, from BioCen, Habana, Cuba, for their material help and cooperation to complete this work.

\section{References}

1.SIERRA, V.G., TAMARGO, S.B., Rev. Anales ACC, 1, nr. 2, 2011, p.1.
2.SCHIJ NS, V.E., Unravelling the immunologists dirty little secret, in: Schijns, V.E., O'Hagan, D.T. (Eds.), Immunopotentiators in Modern Vaccines, 1st ed. Elsevier Academic Press, USA, 2006, pp. 1-16.

3.GOTO, N., KATO, H., MAEYAMA, J.I., ETO, K., YOSHIHARA, S., Vaccine, 11, 1993, p. 914.

4.EBENSEN, T., GUZMAN, A.C., Human Vaccines, 4, nr. 1, 2008, p. 13. 5.SIERRA, G.V., CAMPA, H. C., VARCACEL, N. M., GARCIA, I. L. et al., NIPH Ann., 14, 2, 1991, p. 195.

6.TAMARGO SANTOS, B., FLEITAS, PEREZ C., INFANTE BOURZAC, J.F., MARQUEZ NAPOLES, Y., RAMIREZ GONZALEZ, W., BOURG, V., TORRALBA, D., PEREZ, V., MOURINO, A., AYALA, J., LABRADA, ROSADO, A., ALEYA, L., BUNGAU, S., SIERRA GONZALEZ, V.G., Sci. Total Environ., 668, 2019, p. 1055. https://doi.org/10.1016/ j.scitotenv. 2019.03 .075

7.ULI, L, CASTELLANOS-SERRA, L., BETANCOURT, L., DOMINGUEZ, F., BARBERA, R., SOTOLONGO, F., et al. Proteomics, 6, nr. 11, 2006, p. 3389.

8.PERKINS, B.A., JONSDOTTIR, K., BRIEM, H., GRIFFITHS, E., PLIKAYTIS, B.D., HOIBY, E.A., et al., J. Infect. Dis., 177, 1998, p. 683. 9.OCHOA-AZZE, R.F., GARCIA-IMIA, L., VEREZ-BENCOMO, V., MEDICC Review, 20, nr. 3, 2018, p. 22.

10.PEREZ, O., LASTRE, M., LAPINET, J., BRACHO, G., DIAZ, M., SIERRA, V.G., et al., Infect. Immun., 69(7), 2001, p. 4502.

11.RODRIGUEZ, T., PEREZ, O., UGRINOVIC, S., BRACHO, G., MASTROENI, P., Vaccine, 24, nr. 2, 2006, p. 24.

12.PEREZ, O., BRACHO, G., LASTRE, M., MORA, N., DEL CAMPO, J., GIL, D., et al., Immunol. Cell. Biol., 82, 2004, p. 603.

13.GOULD-FOGERITE, S., ZHANG, F., MANNINO, R.J., Cochleate vaccines for mucosal and systemic immunization, in: Girard, M. (Eds), Retroviruses of Human AIDS and Related Animal Diseases. Elsevier Science \& Technology, Paris, France, 2000, pp. 215-222.

14.ZARIF, L., GRAYBILL, J.R., PERLIN, D., NAJVAR, L., BOCANEGRA, R., MANNINO, R.J ., Antimicrob. agents chemother., 44, nr. 6, 2000, p. 1463.

15.NOSSAL, G.J.V., Vaccines, in: Paul, W.E. (Eds), Fundamental Immunology. Lippincott Williams \& Wilkins, New York, 2003.

16.ZOLNIK, B.S., GONZALEZ-FERNANDEZ, A., SADRIEH, N., DOBROVOLSKAIA, M.A., Endocrinology, 151, 2010, p. 458.

17.KAPLANSKI, C., LEBRON, J., WOLF, J., LEDWITH, B., Immunotoxicological concerns for vaccines and adjuvants, in: Herzyk, D.J., Bussiere, J.L. (Eds.), Immunotoxicology Strategies for Pharmaceutical Safety Assessment Vaccines and Adjuvants, 1st ed. John Wiley \& Sons, New York, USA, 2008, pp. 229-237.

18.LINDBLAD, E.B., Safety evaluation of vaccine adjuvants, in: Singh, M. (Eds), Vaccine Adjuvants and Delivery Systems, 1st ed. WileyInterscience, New York, 2007, pp. 421-444.

19.BATISTA, A., LINDBLAD, E.B., OVIEDO, E., Toxicol. Lett., 203, 2011, p. 97.

20.KIRBY, C., GREGORIADIS, G., Nature Biotechnol., 2, 1984, p. 979. 21.PAPAHADJ OPOULOS, D., VAIL, W.J ., J ACOBSON, K., POSTE, G., Biochim. Biophys., 394, 1975, p. 483.

22.GALBIATI, V., MITJANS, M., CORSINI, E., J. Immunotoxicol., 2010, 7, nr. 4, p. 255.

23.GUPTA, R.K., RELYVELD, E.H., LINDBLAD, E.B., BIZZINI, B., BENEFRAIM, S., GUPTA, C.K., Vaccine, 11, 1993, p. 293.

24.DOBROVOLSKAIA, M.A., MCNEIL, S.E., Nat. Nano., 2, 2007, p. 469. 25.SHVEDOVA, A.A., KISIN, E.R., MERCER, R., MURRAY, A.R., JOHNSON, V.) ., POTAPOVICH, A.I., et al., Am. J. Physiol. Lung. Cell. Mol. Physiol., 289, 2005, p. 698.

26.XIANG, S.D., SCHOLZEN, A., MINIGO, G., DAVID, C., APOSTOLOPOULOS, V., MOTTRAM, P.L., et al., Methods, 40, 2006, p. 1.

27.MITCHELL, L.A., LAUER, F.T., BURCHIEL, S.W., MCDONALD, J.D., Nat. Nanotechnol., 4, 2009, p. 451.

28.MANCEBO, A., SCULL, I., GONZALEZ, Y., ARTEAGA, M.E., GONZALEZ, B.O., FUENTES, D., et al., Rev. Toxicol., 2002, p. 73.

29.*** USP 33-NF 28 Reissue New and Revised Official Text Since the Second Supplement to USP 32-NF 27. 2010. 
30.SHAYNE, C.G., Animal models in toxicology, 2nd ed. Taylor \& Francis, New York, USA, 2007.

31.INFANTE, J.F., SIERRA, V.G., CAMPA, H.C., MUNOZ, C.E., PEREZ, A.V., VacciMonitor, 9, 1997, p. 10.

32.THEIN, P., Not. Med. Vet., 59, 1998, p. 3-7.

33.CO, D.O., HOGAN, L.H., IL-KIM, S., SANDOR, M., Immunol. Lett., 92, 2004, p 135.

34.GHERARDI, R.K., COQUET, M., CHERIN, P., BELEC, L., MORETTO, P., DREYFUS, P.A., et al., Brain, 124, nr. 9,2001, p. 1821.

35.LYKE, M., Cell Microbiol., 6, nr. 1, 2004, p. 23.

36.LOPEZ, Y., SIFONTES, S., INFANTE, J.F., DIAZ, D., OBAYA, M., ALVAREZ, E., et al., VacciMonitor, 14, nr. 2, 2005, p. 1.

37.NUNEZ, J.F., HERRERA, L., INFANTE, J.F., GONZALEZ, P., PEREZ, V., ARGAMACILLA, M., et al., VacciMonitor, 15, nr. 2, 2006, p. 1.

38.SIEGRIST, C.A., Arch. Pediatrie., 12 nr. 1, 2005, p. 96.

39.LACSON, A.G., D'CRUZ, C.A., GILBERT-BARNESS, E., SHARER, L., JACINTO, S., CUENCA, R., Pediatric Develop. Pathol., 5, nr. 2, 2002, p. 151.

40.LACH, B., CUPLER, E.J., J. Child Neurol. 23, nr. 6, 2008, p. 614.

41.AUTHIER, F.J., SAUVAT, S., CHRISTOV, C., CHARIOT, P., RAISBECK, G., PORON, M.F., YIOU, F., GHERARDI, R., Neuromuscul. Disord., 16, nr. 5, 2006, p. 347.

42.AUTHIER, F.J., CHERIN, P., CREANGE, A., BONOTTE, B., FERRER, X., ABDELMOUMNI, A., et al., Brain, 124, 2001, p. 974.

43.SPICKLER, A.R., ROTH, J.A., J. Veter. Internal Med., 17, 2003, p. 273.
44.GIZURARSON, S., GEORGSSON, G., AGGERBECK, H., THORARINSDOTTIR, H., HERON, I., Toxicology, 107, 1996, p. 61.

45.ILLUM, L., J. Controlled Release, 87, 2003, p. 187.

46.INFANTE, J .F., SIFONTES, S., PEREZ, V., BRACHO, G., HERNANDEZ, T., ZAYAS, C., et al., VacciMonitor, 18, nr. 1, 2009, p. 1.

47.BURLESON, G.R., BURLESON, F.G., J. Immunotoxicol., 5, 2008, p. 23.

48.KUPER, C.F., Experim. Toxicologic Pathol., 57, 2006, p. 363.

49.ENDRES, L., TIT, D.M., BUNGAU, S., CIOCA, G., ABDEL-DAIM, M., BUHAS, C., POP, O., SAVA, C., Rev. Chim.(Bucharest), 69, no. 12, 2018, p. 3675

50.SZASZ, F., LEVAI, C., NAVOLAN, D., FARCAS, S., ANDREESCU, N., BIRSASTEANU, F., MEHEDINTU, C., IONESCU, C.A., BOHILTEA, R., CARABINEANU, A., NEMESCU, D., SIMU, S., STOIAN, D., Rev. Chim.(Bucharest), 69, no. 2, 2018, p. 529.

51.SCHULTE, A., ALTHOFF, J., EWE, S., Regul. Toxicol. Pharmacol., 36, 2002, p. 12.

52.ABDEL-DAIM, M.M., ZAKHARY, N.I., ALEYA, L., BUNGAU, S.G., BOHARA, R.A., SIDDIQI, N.J., Oxidat. Med. Cell. Longev., 2018, 2018, ID 2098123. https://doi.org/10.1155/2018/2098123

53.FARARJEH, M., MOHAMMAD, M.K., BUSTANJI, Y., ALKHATIB, H., ABDALLA, S., Internat. Immunopharmacol., 8, 2008, p. 341.

54.KIM, H.S., EOM, J.H., CHO, H., CHO, Y.J ., KIM, J.Y., LEE, J.K., et al., J. Toxicol. Environ. Health, 70, 2007, p. 1278.

Manuscript received: 6.11 .2018 